\title{
PATRIMONIO Y PAISAJE EN ESPAÑA Y PORTUGAL. DEL VALOR SINGULAR A LA INTEGRACIÓN TERRITORIAL
}

\author{
María Isabel Martín Jiménez \\ Departamento de Geografia. Universidad de Salamanca \\ imaj@usal.es
}

\section{RESUMEN}

El artículo recoge algunas reflexiones sobre los conceptos de patrimonio y de paisaje y su evolución, que trascienden a la normativa y también a la clasificación de los diferentes bienes, como se aprecia en las recomendaciones a escala internacional y en el recorrido comparado que hacemos por la legislación y los bienes clasificados en España y en Portugal.

Se parte de una consideración individual del patrimonio ligado al arte, a la naturaleza o la historia -el monumento- y se analiza cómo se van incorporando aspectos culturales hasta desembocar en el paisaje y el patrimonio territorial, fruto de la interacción entre el grupo humano y la naturaleza en un espacio determinado a lo largo del tiempo; son pues un «palimpsesto» que conserva las huellas de generaciones anteriores y sobre el que ponemos nuevas letras, hasta integrarse en las políticas territoriales como un recurso para el desarrollo.

Palabras clave: Patrimonio, Espacios Naturales, Bienes culturales, Conservación, Ordenación del Territorio.

\section{ABSTRACT}

The article explores the concepts of heritage and landscape and their evolution as used in regulations and heritage classifications. The ways in which these concepts are valued as policy recommendations at an international scale are described. Special attention is paid to the improvement of legislation and recognized heritage in Spain and Portugal.

Fecha de recepción: septiembre 2014.

Fecha de aceptación: mayo 2015. 
The analysis departs from 'the monument', which is the heritage related to art, nature or history. Subsequently, it is analyzed how cultural aspects are being incorporated and how they finally become part of landscape and territorial heritage. This long-term process is a result of interaction between groups of human beings and nature within a certain space. Territorial heritage is a 'palimpsest' that preserves the traces of former generations to which we attribute a new content, which goes as far as to integrate it as a development resource into regional policies.

Keywords: Heritage, Natural Spaces, Cultural Assets, Preservation, Regional Planning.

\section{INTRODUCCIÓN}

El acercamiento entre paisaje y patrimonio es relativamente reciente -me atrevería a decir que apenas veinte años-, por eso cuando hablamos de paisaje la memoria nos transporta al medio natural y cuando decimos patrimonio lo relacionamos con el arte y la historia, con los monumentos sensu stricto, y esta dicotomía tiene que ver con la toma de conciencia en el mundo occidental -europeo- de la necesidad de conservar el legado recibido de nuestros antepasados y de transmitir esa herencia a nuestros descendientes.

Es bien conocido que esa toma de conciencia surge cuando la sociedad industrial, la ciudad moderna, introduce una ruptura, una fuerte discontinuidad, con el pasado y ante el riesgo de destrucción-desaparición tanto de edificios insignes como de lugares singulares, se empieza a defender el patrimonio histórico y artístico, en Europa, y el patrimonio natural, la belleza y la armonía de los paisajes en el lado americano, en Estados Unidos. Solo dos referencias para rememorarlo: la defensa del París medieval frente al París burgués de Hussmann y Napoleón III; la declaración del Parque Nacional de Yelowstone en las Montañas Rocosas en 1872 (Ortega, 1998: 34).

A partir de esas reflexiones desde los diferentes ámbitos del saber y de la ciudadanía se ve la necesidad de conservar el legado recibido, se suceden las normas y leyes encaminadas a su protección y se elaboran los inventarios de patrimonio histórico, artístico y natural por los diferentes Estados, al tiempo que evoluciona el concepto y el significado de ambos hasta su consideración conjunta como patrimonio territorial y su entronque con la ordenación del territorio.

\section{EL PASO DEL «MONUMENTO» AL «PATRIMONIO» EN LAS RECOMENDACIONES INTERNA- CIONALES}

$\mathrm{Al}$ acercarnos a la noción de patrimonio y su relación con el territorio vemos en primer lugar, como ya apuntábamos, que es una concepción relativamente nueva y que los enfoques han ido mudando. De manera muy sintética podemos decir que se pasa del monumento al monumento histórico, del monumento histórico al conjunto histórico, y de ahí al patrimonio cultural y natural que desemboca en el paisaje cultural. Si repasamos las recomendaciones y normas a escala internacional, impulsadas a partir de 1945 por la UNESCO -Organización de las Naciones Unidas para la Educación, la Ciencia y la Cultura-, vemos como se recoge esta evolución. 
La primera cita en este repaso es la Carta de Atenas de 1931, de conservación de monumentos de Arte e Historia, que centra sus esfuerzos en salvaguardar las obras maestras en las cuales la civilización ha encontrado su más alta expresión. De forma clara señala que:

«Considera altamente deseable que las instituciones y los grupos calificados, sin menoscabo del derecho público internacional, puedan manifestar su interés para la salvaguarda de las obras maestras en las cuales la civilización ha encontrado su más alta expresión y que aparecen amenazadas» (Carta de Atenas: punto 1).

Se deduce, por tanto, que las obras maestras, el monumento, como tal, es la principal preocupación y en ellas se deben centrar todos los esfuerzos para su conservación y preservación.

Años más tarde, en la Carta de Venecia de 1964 para la conservación y la restauración de monumentos y sitios, el foco sigue puesto en los monumentos, aunque se incorporan aspectos históricos y se añade, al valor creativo de las obras singulares, el significado cultural. Así se recoge en la definición de monumento histórico que incorpora la carta y que reproducimos:

«La noción de monumento histórico comprende tanto la creación arquitectónica aislada, como el ambiente urbano o paisajístico que constituya el testimonio de una civilización particular, de una evolución significativa o de un acontecimiento histórico. Esta noción se aplica no sólo a las grandes obras, sino también a las obras modestas que con el tiempo hayan adquirido un significado cultural» (Carta de Venecia: artículo 1, definiciones).

La contemplación de las obras maestras, no solo en si mismas sino también en relación con el tiempo y con el espacio, es una línea abierta en la que se ha ido avanzando y en el siguiente hito vemos como se ha pasado de lo singular, en su valoración artística y en sus coordenadas espacio-temporales, a un concepto más global como es el patrimonio que incorpora también el valor natural.

La Convención sobre la protección del Patrimonio Mundial Cultural y Natural, auspiciada en 1972 por la $\mathrm{UNESCO}^{1}$, en su primer apartado ofrece las definiciones de patrimonio cultural y natural y acota diferentes categorías, desde monumentos a conjuntos o lugares, como sigue:

«A los efectos de la presente Convención se considerará «patrimonio cultural»:

- Los monumentos: obras arquitectónicas, de escultura o de pintura monumentales, elementos o estructuras de carácter arqueológico, inscripciones, cavernas y grupos de elementos, que tengan un valor universal excepcional desde el punto de vista de la historia, del arte o de la ciencia.

- Los conjuntos: grupos de construcciones, aisladas o reunidas, cuya arquitectura, unidad e integración en el paisaje les dé un valor universal excepcional desde el punto de vista de la historia, del arte o de la ciencia,

1 Conferencia General de la Organización de las Naciones Unidas para la Educación, la Ciencia y la Cultura, en su $17^{\circ}$ Reunión celebrada en París del 17 de Octubre al 22 de Noviembre de 1972. 
- Los lugares: obras del hombre u obras conjuntas del hombre y la naturaleza así como las zonas, incluidos los lugares arqueológicos que tengan un valor universal excepcional desde el punto de vista histórico, estético, etnológico o antropológico.

A los efectos de la presente Convención se consideran «patrimonio natural»:

- Los monumentos naturales constituidos por formaciones físicas y biológicas o por grupos de esas formaciones que tengan un valor universal excepcional desde el punto de vista estético o científico.

- Las formaciones geológicas y fisiográficas y las zonas estrictamente delimitadas que constituyan el hábitat de especies animal y vegetal amenazadas, que tengan un valor universal excepcional desde el punto de vista estético o científico.

- Los lugares naturales o las zonas naturales estrictamente delimitadas, que tengan un valor universal excepcional desde el punto de vista de la ciencia, de la conservación o de la belleza natural» (UNESCO, 1972: artículos 1 y 2).
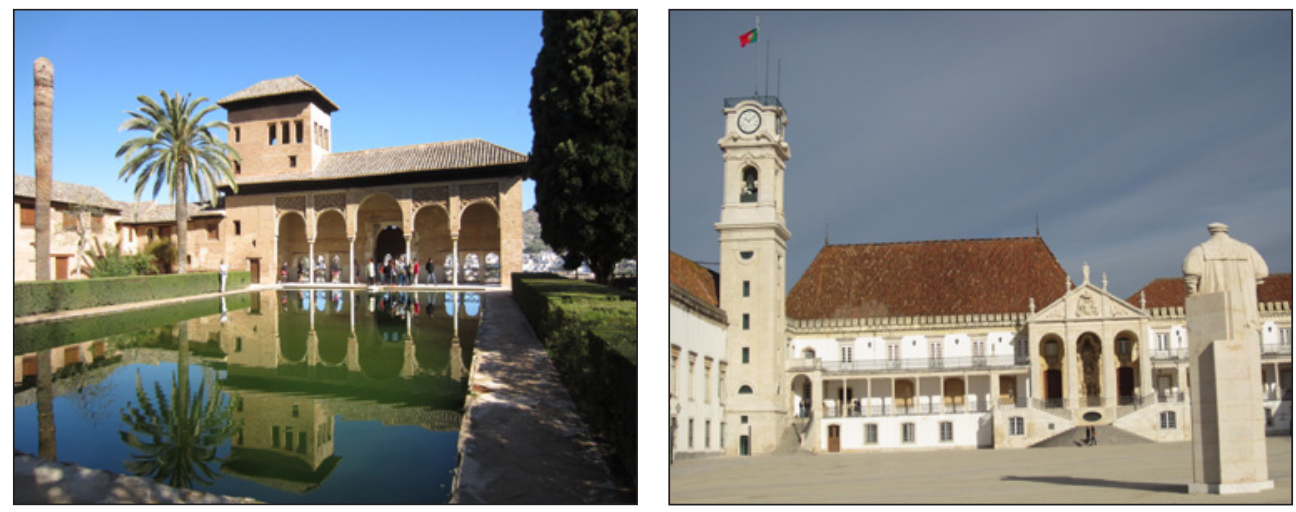

Fuente: elaboración propia.

En esta evolución se da un paso más en 1992, cuando el Comité de la Convención del Patrimonio Mundial, en su decimosexta reunión acepta que los paisajes culturales formen parte del patrimonio Mundial de la Humanidad ${ }^{2}$ y los reconoce como «obras combinadas de la naturaleza y el hombre», en consonancia con la definición recogida en el Artículo 1 de la Convención de 1972 referida a los lugares incluidos en el patrimonio cultural. De forma expresa en la reunión de 1992 se aprueba la revisión de los criterios de los bienes culturales y la inclusión de la categoría de paisajes culturales (UNESCO, 1992, punto XIII.2.2, 58).

2 Pueden verse las referencias al paisaje cultural en http://whc.unesco.org/fr/sessions/ http://whc.unesco.org/ en/culturallandscape/\#1 y en http://www.icomos.org/landscapes/index2esp.htm 
Cuando se desarrolla este aspecto se especifica que «los paisajes culturales reflejan con frecuencia técnicas específicas de uso sostenible de la tierra, tomando en consideración las características y límites del entorno natural en el que están establecidas, y una relación espiritual específica con la naturaleza» (UNESCO, 1994: punto 38) y se distinguen tres categorías:

- La primera categoría es el «paisaje claramente diseñado y creado intencionalmente por el hombre. Abarca paisajes de jardines y parques construidos por razones estéticas que están generalmente (pero no siempre) asociados con construcciones y conjuntos de monumentos religiosos o de otras clases».

- La segunda categoría «es el paisaje orgánicamente evolutivo. Es el resultado de un imperativo inicial social, económico, administrativo, y/o religioso; y ha desarrollado su forma actual en asociación con y en respuesta a su entorno natural. Tales paisajes reflejan ese proceso de evolución en su forma y las características de sus componentes.

Se subdivide en dos subcategorías:

- Un paisaje cultural relicto (o fósil) es aquel en el que un proceso de evolución finalizó en algún momento del pasado, tanto abruptamente como a lo largo de un cierto tiempo. Sin embargo, sus características significativas son todavía visibles en forma material.

- Un paisaje vivo es uno que mantiene un papel social activo en la sociedad contemporánea asociado con el modo de vida tradicional, en el cual el proceso de evolución está aún en progreso. Al mismo tiempo muestra evidencia material significativa de su evolución en el tiempo».

- La categoría final «es el paisaje cultural asociativo. La inclusión de tales paisajes en la Lista de Patrimonio de la Humanidad se justifica en virtud de las poderosas asociaciones religiosas, artísticas o culturales del elemento natural más que en evidencia cultural material, que puede ser insignificante o incluso ausente».(UNESCO, 1994: punto 39).

Llegados a este punto hemos visto como los desvelos por la conservación de la herencia recibida de nuestros antepasados ha evolucionado, como ya hemos mencionado, desde la visión restringida a los monumentos o a los valores naturales, a la noción más integral del patrimonio cultural y a la incorporación reciente del paisaje, el entorno, el territorio en su conjunto y el papel activo de la sociedad que lo habita, y de esta forma enlaza con el patrimonio territorial, del que luego hablaremos ${ }^{3}$, y se convierte en un recurso de primer orden que adquiere un valor mercantil (Gómez-Mendoza, 2013: 17). Veamos antes cómo estas cuestiones planteadas a escala internacional se trasladan al ámbito nacional.

3 A los cuatro hitos repasados podríamos añadir el Convenio Europeo del Paisaje, acordado en Florencia el 20 de octubre del año 2000 bajo los auspicios del Consejo de Europa, que avanza en la consideración del paisaje como un valor patrimonial y territorial. Asimismo, queremos citar la Convención de la UNESCO del año 2003, que pone el acento en el patrimonio cultural inmaterial, aunque este aspecto se aparta de los propósitos de este artículo. 


\section{LAS NORMATIVAS NACIONALES DE CONSERVACIÓN DEL PATRIMONIO}

El repaso de las normativas nacionales de España y Portugal en lo relacionado con la preservación del patrimonio reproduce en buena medida el camino recorrido a escala mundial en lo que atañe a la protección de los valores artísticos, históricos y culturales, aunque no llega a imbricarse claramente con los valores naturales, que han tenido una consideración en parte desligada de lo señalado con anterioridad y con normas claramente diferenciadas.

\section{III.1. Legislación portuguesa}

En el caso de Portugal, la preocupación por la salvaguarda de «las antigüedades» se retrotrae al siglo XVIII y están ligadas a la Real Academia de la Historia cuando en 1771 instruye que: «daqui em diante nenhuma pessoa de qualquer estado, qualidade e condição que seja, [possa] desfazer ou destruir, em todo ou em parte, qualquer edifício que mostre ser daqueles tempos (assim designados Fenícios, Romanos, Godos e Arábios), ainda que esteja arruinado e da mesma sorte as estátuas, mármores e cipos...» (França, 1996: 25). Quizás en esta decisión influyó el hecho de que tras los efectos demoledores del terremoto «de Lisboa» de 1755 los edificios derruidos fueron desmantelados sin distinción alguna.

Habrá que esperar casi un siglo para que el interés por el patrimonio heredado pase a las más altas esferas del Estado y el Ministerio de Obras Públicas solicite a la Real Asociación de Arquitectos y Arqueólogos una lista de monumentos «a clasificar», si bien el inicio de la preservación de los bienes inmuebles se sitúa en el Decreto del 24 de octubre de 1901, que reorganiza el Consejo Nacional dos Monumentos de la Dirección General de Obras Públicas y Minas y determina que la clasificación de los monumentos nacionales sea hecha por Decreto publicado en el boletín oficial (Barbero, 2011: 599). En 1906 se formaliza una primera clasificación de monumentos, aunque hay que esperar hasta 1910 para que en el Diario del Gobierno de 23 de Junio, recoja una clasificación detallada y ordenada por categorías: monumentos pre-históricos (antas e outros monumentos), monumentos lusitanos e lusitanoromanos (castros, entrincheiramento, povoações, castellos, marcos milliarios, pontes, templos, arcos, fontes, estatuas, inscrições y ruinas) y monumentos medievales, do renascimento e modernos, clasificados asimismo como monumentos religiosos (cathedraes, mosteiros, basílicas, igrejas, capellas, cruzeiros e túmulos e sepulturas), monumentos militares (castellos, torres y padrões) y monumentos civis (paços reaes, paços municipaes, paços episcopaes, paços de universidade e palacios particulares e casas memoraveis, misericordias e hospitaes, aqueductos, chafarizes e fontes, pontes, arcos e padrões commemorativos, pelourinhos y trechos architectonicos) (IPPAR, 1994). Por supuesto, en el referido Decreto de 1910 se detallan qué monumentos tienen las categorías señaladas contabilizando 57 prehistóricos, 48 lusitanos y romanos y 358 medievales, del renacimiento y modernos (169 religiosos, 68 militares y 121 civiles).

En este primer catálogo prima el carácter monumental de la obra de arte y los aspectos históricos, como se ve con claridad en el primer nivel de la clasificación. Con posterioridad se sucederán distintas declaraciones que incorporan además el «interés público» o el «valor para el municipio» entre los requisitos para que un bien sea catalogado como monumento, 
al tiempo que se señala la posibilidad de proteger también su entorno (Ferreira Pires, 2013: 278, Decreto 21.875 de 1932). Se introducen así los aspectos culturales que se mantendrán en buena medida en las regulaciones posteriores.
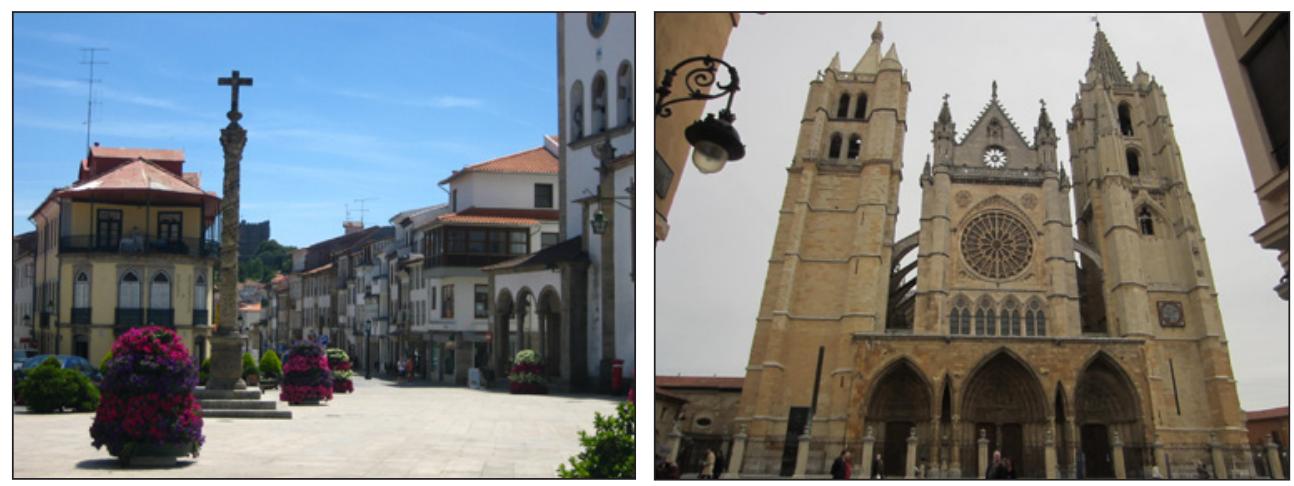

Fuente: elaboración propia.

Será en 1985 cuando se regule por Lei 13/85 el patrimonio según las recomendaciones internacionales y se establecerán las categorías de monumento, conjunto y sitio graduadas según su valor local, regional, nacional o internacional. Al mismo tiempo se asigna la gestión de dicho patrimonio al Instituto de Gestão do Patrimônio Arquitetônico e Arqueológico (IGESPAR).

La Lei 107/2001, de 8 de Setembro, reemplaza a la anterior y aunque recoge en buena medida las cuestiones allí planteadas, avanza en la necesidad de poner en uso y en valor el patrimonio, no en vano dicha ley «Estabelece as bases da política e do regime de protecção e valorização do património cultural», avanzando en la línea ya observada a escala internacional; en ella se puede leer:

«...integram o Património cultural todos os bens que, sendo testemunhos com valor de civilização e cultura portadores de interesse cultural relevante, devam ser objeto de especial proteção e valorização.» (Lei 107/2001: artículo 2.1).

Además, esta consideración del patrimonio como bienes que han de tener un uso y un valor se refuerza con la reorganización administrativa y las funciones tanto de la Dirección General del Patrimonio Cultural como de las direcciones regionales, aunque la gestión sigue en manos del IGESPAR -Instituto de Gestão do Patrimônio Arquitetônico e Arqueológico-.

En cuanto a la protección de los espacios naturales no tenemos que retrotraernos en demasía, pues hasta fechas relativamente recientes no hay una norma específica. La Lei 9/70 de 19 de junio de parques nacionales y otros tipos de reservas fue la que abrió la puerta para la creación del primer y único Parque Nacional que hasta el momento tiene catalogado Por- 
tugal, el de Peneda-Gerês en 1971. Posteriormente, la Lei 11/87 de bases do ambiente, dará paso a la concreción de diferentes tipologías de áreas protegidas por sus valores naturales (Parque Nacional, Parque Natural, Reserva Natural, Paisaje Protegido, Monumento Natural y Área Protegida Privada) Al mismo tiempo esta norma incorpora sin ambages las consideraciones relativas al paisaje, que define como sigue:

«c) Paisagem é a unidade geográfica, ecológica e estética resultante da acção do homem e da reacção da Natureza, sendo primitiva quando a acção daquele é mínima e natural quando a acção humana é determinante, sem deixar de se verificar o equilíbrio biológico, a estabilidade física e a dinâmica ecológica» (Lei 11/1987: artículo 5, punto 2 c).

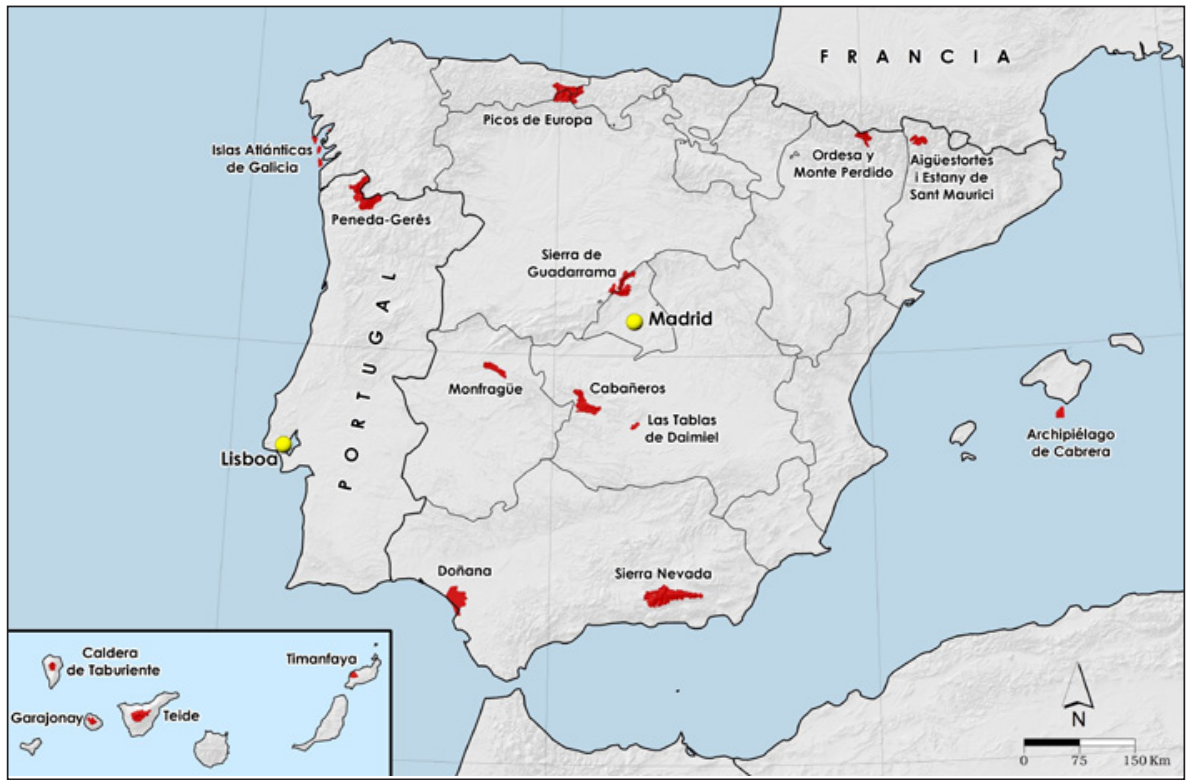

Fuente: Ministerio de Agricultura, Alimentación y Medio Ambiente. http://www.magrama.gob.es/es/red-parquesnacionales/nuestros-parques/. Elaboración propia.

Esta ley atiende asimismo a la necesaria consideración conjunta del patrimonio cultural y natural, si bien se siguen vías diferenciadas en la regulación y gestión de cada uno de ellos; en el artículo 20 se señala:

«1 - O património natural e construído do País, bem como o histórico e cultural, serão objecto de medidas especiais de defesa, salvaguarda e valorização, através, entre outros, de uma adequada gestão de recursos existentes e planificação das acções a empreender numa perspectiva de animação e utilização criativa. 
2 - Legislação especial definirá as políticas de recuperação de centros históricos de áreas urbanas e rurais, de paisagens primitivas e naturais notáveis e de edifícios e conjuntos monumentais e de inventariação e classificação do património histórico, cultural, natural e construído, em cooperação com as autarquias e com as associações locais de defesa do património e associações locais de defesa do ambiente, e estabelecerá a orgânica e modo de funcionamento dos organismos, existentes ou a criar, responsáveis pela sua execução» (Lei 11/1987: artículo 20) ${ }^{4}$.

De este breve recorrido por la legislación se infiere el tránsito del monumento histórico, al patrimonio cultural y natural y al paisaje cultural, según la senda marcada por las instituciones internacionales, y como se ha sumado al valor intrínseco de los mismos, por sus propios elementos, un valor de uso, al que claramente se refiere el último texto citado.

\section{III.2. Legislación española}

En España el devenir de la preocupación por salvaguardar la herencia patrimonial avanza por un camino similar al ya señalado para Portugal. Así, las primeras llamadas de atención se retrotraen al siglo XVIII y están ligadas a la Real Academia de la Historia y a la Real Academia de Bellas Artes de San Fernando; una dicotomía que refleja la vinculación de los monumentos con el valor que les otorga la historia nacional y su sentido artístico (GómezMendoza, 2013: 11). En estos inicios el patrimonio se asocia directamente con el monumento y la antigüedad como podemos leer en la Real Cédula de Carlos IV de 1803:

«Por monumentos antiguos se deben entender las estatuas, bustos y baxos relieves, de qualesquiera materia que sean, templos, sepulcros, teatros, anfiteatros, circos, naumachîas, palestras, balos, calzadas, caminos, aqüeductos, lápidas ó inscripciones, mosaycos, monedas de qualquiera clase, camafeos, trozos de arquitectura, colunas miliarias... y finalmente qualesquiera cosas, aun desconocidas, reputadas por antiguas, ya sean Púnicas, Romanas, Cristianas, ya Godas, Árabes y de la baxa edad» (Real Cédula, 1803: Punto 1).

A lo largo del siglo XIX se suceden normas relacionadas con la custodia de los «monumentos artísticos del reino» y los encargados de velar por ellos (Barrero, 1990), al tiempo que se inicia la catalogación de monumentos de forma individual, sin atender a ninguna clasificación y movidos fundamentalmente por la necesidad de preservarlos o evitar su venta 5 . La Ley de 4 de marzo de 1915 relativa a los monumentos nacionales arquitectónicos-artísticos recoge en su artículo primero la necesidad de proceder a una declaración formal de los mismos $^{6}$, aunque se continúa catalogando de manera individual.

4 La Lei 19/2014, de 14 de Abril, que define as bases da política de ambiente, mantiene el mismo texto.

5 Es bien conocido que la Catedral de León fue el primer monumento catalogado en España por la Real Orden de 28 de agosto de 1844 (Parrondo Acero, 1973: 27).

6 Para hacer la declaración formal de monumentos se han de seguir las instrucciones de la Ley de 7 julio de 1911 que encomienda al Ministerio de Instrucción Pública y Bellas Artes la formación de un inventario de las ruinas monumentales y las antigüedades. 
En el inicio del siglo XX hay que destacar no obstante que a los aspectos históricos y artísticos se suma la noción de cultura, de tal forma que en el Real Decreto-Ley de 9 de agosto de 1926, en su artículo 1, se señala que «constituyen el tesoro artístico nacional el conjunto de bienes muebles e inmuebles dignos de ser conservados para la Nación por razones de Arte y cultura» y, además, junto a los elementos singulares se tiene en consideración el entorno de los mismos e, incluso, el conjunto en el que se integran. Según el artículo 20 se «podrá acordar la declaración de ciudades y pueblos artísticos» como parte del Tesoro Nacional. Las categorías de bienes inmuebles recogidas en el artículo 2 de esta norma son: a) monumentos (monumentos históricos, artísticos nacionales o monumentos arquitectónicoartísticos), b) las edificaciones o conjunto de ellas, sitios, y lugares de reconocida y peculiar belleza y c) Los yacimientos y objetos de interés paleontológico y prehistórico, las cuevas, abrigos y peñas, con pinturas rupestres; los monumentos prehistóricos (Megalíticos y cuevas artificiales), en sus distintas especies.

Esta disposición es pionera a escala internacional ya que se anticipa en el tiempo a los principios y criterios de la teoría de los bienes culturales y, por otro lado, considera nuevas tipologías de inmuebles -Sitios Históricos y Conjuntos Históricos- que han perdurado, con matizaciones, hasta la actualidad (Barrero,1990).

Durante la segunda República destaca la referencia al patrimonio histórico artístico en la Constitución: «Toda la riqueza artística e histórica del país, sea quien fuere su dueño, constituye el tesoro cultural de la Nación, y estará bajo la salvaguardia del Estado» (Constitución 1931: artículo 45). Con anterioridad se había decretado una «catalogación en masa» y se habían preservado los bienes con más de cien años de antigüedad ${ }^{7}$ y algún año después, en 1933, se adoptaría la Ley de 13 de mayo relativa al Patrimonio Artístico Nacional. En ella se consagra la antigüedad de las obras «no menor de un siglo» y se establece el término de Patrimonio Histórico Artístico Nacional para «cuantos inmuebles y objetos muebles de interés artístico, arqueológico, paleontológico o histórico haya en España» (artículo 1). En cuanto a su clasificación, los bienes inmuebles se subdividen en «monumentos histórico-artísticos», que aglutinarán a los conjuntos urbanos y a los parajes pintorescos, y yacimientos arqueológicos, aunque no se recoge una definición clara y precisa de cada uno de ellos.

Esta norma republicana fue complementada con numerosas disposiciones como, por ejemplo, las relativas a la conservación, a la exportación de bienes o a la inclusión de determinados tipos de bienes inmuebles como, los castillos o los hórreos, o la defensa del patrimonio documental (Muñoz Cosme, 2012).

La Constitución de 1978 recoge en el artículo 46 que «Los poderes públicos garantizarán la conservación y promoverán el enriquecimiento del Patrimonio histórico, cultural y artístico de los pueblos de España y de los bienes que lo integran, cualquiera que sea su régimen jurídico y su titularidad», pero hay que esperar hasta 1985 para que se promulgue la Ley 16/1985 de 25 de junio del Patrimonio Histórico Español que nos empareja de nuevo con la evolución

7 Decreto, de 3 de junio de 1931, por el que se declaran los Monumentos histórico-artísticos pertenecientes al Tesoro Artístico Nacional. Se declaran más de setecientos edificios distribuidos por todas las provincias españolas duplicando en número al total de inmuebles catalogados hasta la fecha. A esta declaración se suma la Ley de 10 de diciembre de 1931 que impide la enajenación de bienes de más de cien años de antigüedad (García Fernández, 2007). 
legislativa portuguesa ${ }^{8}$ e incorpora las referencias patrimoniales emanadas de los organismos internacionales. La ley reconoce tanto los bienes inmuebles como los muebles y los cataloga a título individual, por su singularidad, o de forma conjunta, quedando establecidos entre los inmuebles los siguientes: «Monumento, Jardines, Conjuntos y Sitio Histórico, así como Zonas Arqueológicas, todos ellos como Bienes de Interés Cultural» (artículo 14. 2.). Junto a esta ley nacional hay que contar a partir de 1990 con las normas autonómicas que son las encargadas de regular las cuestiones referentes al patrimonio en el ámbito de sus territorios (Becerra, 1999: 19) ${ }^{9}$. Es en esta escala regional donde hay que buscar a partir de ahora la incorporación de los aspectos relacionados con la cultura y el paisaje y su ligazón con el patrimonio.

En cuanto a la protección de los espacios naturales con un valor patrimonial vemos que se aborda de forma pionera, enlazando casi en el tiempo con los aires provenientes de Estados Unidos. En 1916 «se crean en España los Parques Nacionales», según reza el artículo primero de la Ley de Parques Nacionales de 7 de diciembre de 1916, y dos años después son declarados como tales la Montaña de Covadonga y el Valle de Ordesa ${ }^{10}$. Los requisitos para alcanzar dicha categoría se centran desde este primer momento en la belleza del paisaje y, también, en sus valores singulares desde el punto de vista natural. En el artículo 2 de la ley se dice que los parques nacionales son «sitios o parajes excepcionalmente pintorescos, forestales o agrestes» y se declaran con el fin de que se «respete la belleza natural de sus paisajes, la riqueza de su fauna y de su flora y las particularidades geológicas e hidrológicas que encierren, evitando de ese modo con la mayor eficacia todo acto de destrucción, deterioro o desfiguración por la mano del hombre».

Figura 4

VALORES NATURALES E HISTÓRICOS DEL PARQUE NACIONAL DE PICOS DE EUROPA;

EN 1916 DECLARADO COMO MONTAÑA DE COVADONGA O PEÑA SANTA DE CASTILLA (MANADA DE CIERVOS Y BASÍLICA DE SANTA MARÍA LA REAL DE COVADONGA)
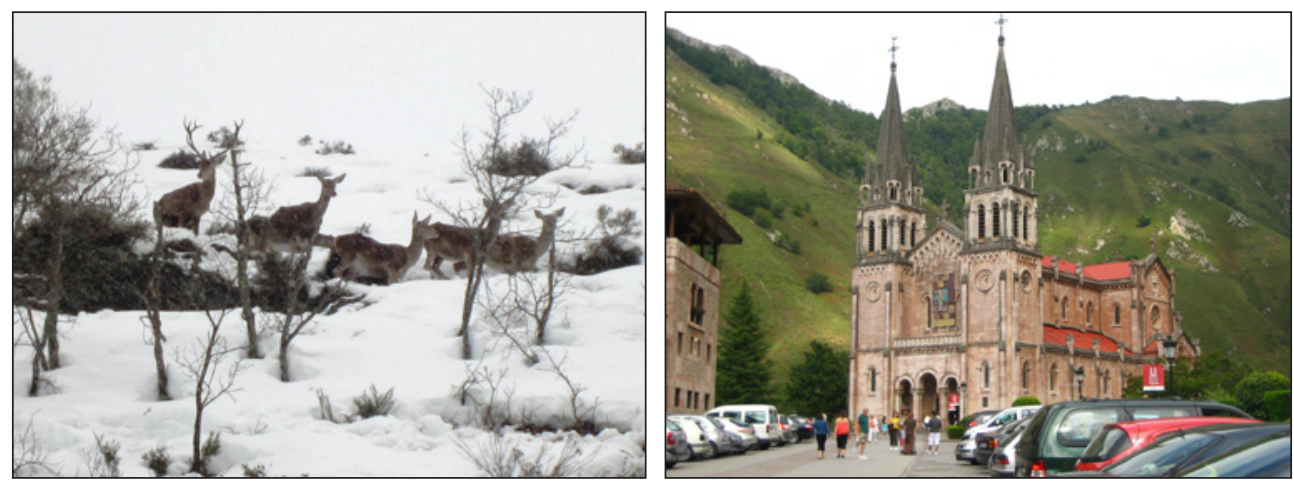

Fuente: elaboración propia.

8 La Ley portuguesa de patrimonio cultural es de 6 de julio de 1985.

9 Las primeras Comunidades Autónomas en contar con una ley propia de patrimonio fueron Castilla la Mancha y el País Vasco.

10 Ambos Parques han sido con posterioridad reclasificados y han cambiado de denominación. Además, el actual Parque Nacional de Ordesa y Monte Perdido está incluido en la lista mundial del Patrimonio de la Humanidad. 
En la Real Orden 176 de 1927 se reconocen las categorías de Sitio de Interés Nacional y Monumento Natural de interés nacional y de nuevo se apela «a su extraordinaria belleza» para ser considerados como tales, de forma análoga a como se exige para la declaración de los sitios históricos en la norma de 1926 referida con anterioridad.

En 1975 la Ley de Espacios Naturales Protegidos unifica las figuras de protección que se habían ido definiendo y/o matizando con anterioridad, y en 1989 se incorporan los «Paisajes protegidos», categoría que se mantiene en la regulación actual junto a Parques, Reservas Naturales, Áreas Marinas Protegidas y Monumentos Naturales (Ley 42/2007). En la Ley de 1989 se define al Paisaje Protegido como «aquellos lugares concretos del medio natural que, por sus valores estéticos y culturales, sean merecedores de una protección especial» (Ley 4/1989: artículo 17), avanzando en alguna medida los argumentos que se recogerán a escala internacional en 1992. En la actual regulación esta conexión es explícita por cuanto se lee que los paisajes protegidos son «partes del territorio que [...] por sus valores naturales, estéticos y culturales, y de acuerdo con el Convenio del Paisaje del Consejo de Europa, [se] consideren merecedores de una protección especial» (Ley 42/2007: artículo 34).

\section{EL PATRIMONIO CLASIFICADO EN ESPAÑA Y PORTUGAL}

Como resultado de la aplicación de las normas señaladas y de los diferentes procesos de catalogación del patrimonio cultural, tanto España como Portugal poseen un buen número de inmuebles clasificados según las diferentes categorías.

A escala internacional, la UNESCO incluyó por primera vez en 1983 tres edificios en suelo peninsular portugués en el listado del Patrimonio Mundial de la Humanidad junto con el Centro de Angra do Heroismo, en las Azores, incorporándose un año después algunos inmuebles españoles. El camino abierto ha continuado y hoy Portugal cuenta con 15 sitios en la referida lista y España con 45, uno de ellos compartido entre ambos países: los Sitios de arte rupestre prehistórico del Valle del Côa y de Siega Verde. La mayoría de sitios -48- responden a la categoría de Bienes culturales y están asociados a diferentes monumentos, aunque también encontramos centros y ciudades históricas e itinerarios culturales, así como 5 más considerados paisajes culturales. A ellos se suman 4 lugares declarados por sus valores naturales y otros 2 en los que se han tenido en cuenta ambos méritos.

Los bienes protegidos a escala internacional están incluidos asimismo en los inventarios de bienes de carácter nacional de cada uno de los dos países. A su lado encontramos otros muchos catalogados según sus respectivas normativas. El repaso de los mismos a partir de las estadísticas oficiales ofrecidas por las instituciones responsables presenta algunas similitudes. En primer lugar, el patrimonio clasificado en el año 2013 es numeroso, 16.795 en España ${ }^{11}$ y 4.308 en Portugal, y destaca la elevada proporción de bienes considerados como monumentos, más de tres cuartas partes del total, en consonancia con el valor dado desde hace siglos a los elementos singulares relacionados con el arte o la historia.

11 En esta cifra se incluyen también los Bienes de Interés Cultural incoados, que ascienden a 1.925 
Tabla 1

EL PATRIMONIO MUNDIAL DE LA HUMANIDAD EN ESPAÑA Y PORTUGAL

\section{BIENES CULTURALES}

\section{ESPAÑA}

-Alhambra, Generalife y Albaicín de Granada (1984, 1994)

-Catedral de Burgos (1984)

-Centro histórico de Córdoba $(1984,1994)$

-Monasterio y sitio de El Escorial en Madrid (1984)

-Obras de Antoni Gaudí (1984, 2005)

-Ciudad vieja de Ávila e iglesias extramuros (1985)

-Ciudad vieja de Santiago de Compostela (1985)

-Ciudad vieja y acueducto de Segovia (1985)

-Cuevas de Altamira y arte rupestre paleolítico del norte de España $(1985,2008)$

-Monumentos de Oviedo y del reino de Asturias $(1985,1998)$

-Arquitectura mudéjar de Aragón (1986, 2001)

-Ciudad histórica de Toledo (1986)

-Ciudad vieja de Cáceres (1986)

-Catedral, alcazar y Archivo de Indias de Sevilla (1987)

-Ciudad vieja de Salamanca (1988)

-Monasterio de Poblet (1991)

-Caminos de Santiago de Compostela. Camino francés y caminos del norte de España (1993, 2015)

-Conjunto arqueológico de Mérida (1993)

-Real Monasterio de Santa María de Guadalupe (1993)

-Ciudad histórica fortificada de Cuenca (1996)

-Lonja de la seda de Valencia (1996)

-Las Médulas (1997)

-Monasterios de San Millán de Yuso y de Suso (1997)

-Palau de la Música Catalana y Hospital de Sant Pau en Barcelona (1997)

\section{BIENES NATURALES}

\section{ESPAÑ}

-Parque Nacional de Garajonay (1986)

-Parque Nacional de Doñana $(1994,2005)$
-Arte rupestre del arco mediterráneo de la Península Ibérica (1998)

-Universidad y barrio histórico de Alcalá de Henares (1998)

-San Cristóbal de La Laguna (1999)

-Conjunto arqueológico de Tarragona (2000)

-Iglesias románicas catalanas de Vall del Boí (2000)

-Muralla romana de Lugo (2000)

-Palmeral de Elche (2000)

-Sitio arqueológico de Atapuerca (2000)

-Paisaje cultural de Aranjuez (2001)

-Conjuntos monumentales renacentistas de Úbeda y

Baeza (2003)

-Puente de Vizcaya (2006)

-Torre de Hércules (2009)

-El Paisaje Cultural de la Serra de Tramuntana (2011)

\section{PORTUGAL}

-Centro de Angra do Heroísmo nos Açores (1983)

-Convento de Cristo em Tomar (1983)

-Mosteiro da Batalha (1983)

-Mosteiro dos Jerónimos e Torre de Belém (Lisboa) (1983)

-Centro histórico de Évora (1986)

-Mosteiro de Alcobaça (1989)

-Paisagem cultural de Sintra (1995)

-Centro histórico do Oporto (1996)

-Centro histórico de Guimarães (2001)

-Alto Douro Vinhateiro (2001)

-Paisagem da Vinha da Ilha do Pico (2004)

-Elvas e suas Fortificações (2012)

-Universidade de Coimbra - Alta y Sofía (2013)

BIENES MIXTOS (culturales y naturales)

ESPAÑA $\quad$-Ibiza, biodiversidad y cultura (1999)

-Pirineos - Monte Perdido (1997, 1999)

\section{BIENES TRANSFRONTERIZOS-TRANSNACIONALES}

-Pirineos - Monte Perdido (1997, 1999) (España-Francia)

-Sitios de arte rupestre prehistórico del Valle del Côa y de Siega Verde (1998, 2010) (España-Portugal)

-Patrimonio del mercurio (Almadén e Idria) (2012) (España-Eslovenia)

Fuente: UNESCO, lista del Patrimonio Mundial de la Humanidad. http://whc.unesco.org/es/list/?iso=es\&search=\& 

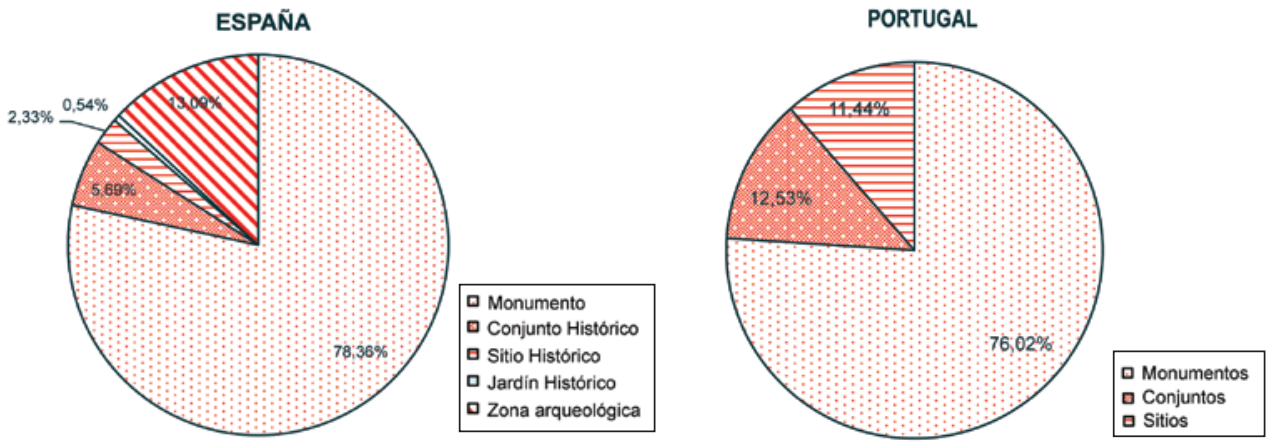

Fuente: Ministerio de Educación, Cultura y Deporte (2014), pág. 225, Direção-Geral do Património Cultural, Direcção Regional da Cultura dos Açores y Direcção Regional dos Assuntos Culturais ${ }^{12}$.

La comparación de las restantes categorías es más difícil establecerla por cuanto las clasificaciones de uno y otro país difieren ${ }^{13}$. Si nos fijamos en los Conjuntos o en los Sitios

12 Tomado de Instituto Nacional de Estatística, 2014, Publicações, Estatísticas da cultura - 2013, Cuadros 6.2.1. a 6.2.4.-Bens Imóveis Classificados, 2013, y consultado El 13 de mayo de 2015 en https://www.ine.pt/xportal/ xmain?xpid=INE\&xpgid=ine_publicacoes\&PUBLICACOESpub_boui=210767363\&PUBLICACOEStema=55554 $\&$ PUBLICACOESmodo $=2$.

13 La Ley 16/1985 de 25 de junio, del Patrimonio Histórico Español, en su artículo 15 define las categorías de bienes inmuebles como sigue:

Monumentos: son aquellos inmuebles que constituyen realizaciones arquitectónicas o de ingeniería, u obras de escultura colosal siempre que tengan interés histórico, artístico, científico o social.

Jardín Histórico: es el espacio delimitado, producto de la ordenación por el hombre de elementos naturales, a veces complementado con estructuras de fábrica, y estimado de interés en función de su origen o pasado histórico o de sus valores estéticos, sensoriales o botánicos.

Conjunto Histórico: es la agrupación de bienes inmuebles que forman una unidad de asentamiento, continua o dispersa, condicionada por una estructura física representativa de la evolución de una comunidad humana por ser testimonio de su cultura o constituir un valor de uso y disfrute para la colectividad. Asimismo es Conjunto Histórico cualquier núcleo individualizado de inmuebles comprendidos en una unidad superior de población que reúna esas mismas características y pueda ser claramente delimitado.

Sitio Histórico: es el lugar o paraje natural vinculado a acontecimientos o recuerdos del pasado, a tradiciones populares, creaciones culturales o de la naturaleza y a obras del hombre que posean valor histórico, etnológico, paleontológico o antropológico.

Zona Arqueológica: es el lugar o paraje natural donde existen bienes muebles o inmuebles susceptibles de ser estudiados con metodología arqueológica, hayan sido o no extraídos y tanto si se encuentran en la superficie, en el subsuelo o bajo las aguas territoriales españolas.

La Lei 13/85 de 6 de Julho do patrimônio Cultural português, en su artículo 8 define las categorías de bienes inmuebles como sigue:

Monumentos: obras de arquitectura, composições importantes ou criações mais modestas, notáveis pelo seu interesse histórico, arqueológico, artístico, científico, técnico ou social, incluindo as instalações ou elementos decorativos que fazem parte integrante destas obras, bem como as obras de escultura ou de pintura monumental.

Conjuntos: agrupamentos arquitectónicos urbanos ou rurais de suficiente coesão, de modo a poderem ser delimitados geograficamente, e notáveis, simultaneamente, pela sua unidade ou integração na paisagem e pelo seu interesso histórico, arqueológico, artístico, científico ou sociale. 
las diferencias son significativas y más aún si nos referimos a los Jardines Históricos o a las Zonas Arqueológicas dado que solo se contemplan en la legislación española. No obstante si podemos relacionar los restos arqueológicos catalogados en ambos países, pues Portugal no los considera una categoría pero si los individualiza como un tipo y las estadísticas nos dicen que hay 533, por tanto, en ambos países los porcentajes sobre el total de bienes inmuebles clasificados son muy similares (el 13,1\% en España, el 12,4\% en Portugal ${ }^{14}$ ).

Tabla 2

BIENES INMUEBLES CATALOGADOS EN ESPAÑA Y PORTUGAL EN 2013

\begin{tabular}{|l|c|c|l|c|}
\hline CATEGORÍAS & ESPAÑA & PORTUGAL & \multicolumn{1}{|c|}{ TIPOLOGÍAS } & PORTUGAL \\
\hline Monumentos & 13.160 & 3.275 & Sitio arqueológico & 533 \\
\hline Conjuntos & 91 & 540 & Arquitectura civil & 2.101 \\
\hline Sítios & 955 & 493 & Arquitectura militar & 285 \\
\hline Jardín Histórico & 391 & & Arquitectura mixta & 36 \\
\hline Zona Arqueológica & 2.198 & & Arquitectura religiosa & 1.353 \\
\hline TOTAL & $\mathbf{1 6 . 7 9 5}$ & $\mathbf{4 . 3 0 8}$ & TOTAL & $\mathbf{4 . 3 0 8}$ \\
\hline
\end{tabular}

Fuente: Ministerio de Educación, Cultura y Deporte (2014), pág. 225, Direção-Geral do Património Cultural, Direcção Regional da Cultura dos Açores y Direç̧ão Regional dos Assuntos Culturais ${ }^{15}$. Elaboración propia.

En lo referente a los bienes naturales vemos que los estimados a escala internacional están contemplados igualmente por las normativas nacionales ${ }^{16}$. La regulación de los espacios naturales se inicia en Portugal de 1970, como ya anticipábamos, y cuenta con un solo Parque Nacional. En la red de áreas clasificadas (Decreto-Lei 19/1993) se integran además 14 Parque Naturales, 14 Reservas Naturales, 11 Paisajes Protegidos, 7 Monumentos Naturales y un Área Protegida Privada, según las categorías recogidas en la normativa ${ }^{17}$, y su valor

Sítios: obras do homem ou obras conjuntas do homem e da natureza, espaços suficientemente característicos e homogéneos, de maneira a poderem ser delimitados geograficamente, notáveis pelo seu interesse histórico, arqueológico, artístico, científico ou social.

14 La normativa Portuguesa contempla los Sitios Arqueológicos como una tipología junto con la Arquitectura Civil, Arquitectura Militar, Arquitectura Mixta o Arquitectura Religiosa (Instituto Nacional de Estatística, 2014).

15 Ver nota 12

16 Nos referimos a los incluidos en el Patrimonio Mundial de la Humanidad; en este apartado no tendremos en cuenta los espacios naturales protegidos por otras normas internacionales y reconocidos en las legislaciones nacionales, como las Reservas de la Biosfera, los Humedales de Importancia Internacional o los Geoparques, entre otros.

17 En Portugal el Decreto Lei 142/2008 define las siguientes áreas clasificadas:

Parque Nacional es un área que contenga mayoritariamente muestras representativas de las regiones naturales características, del paisaje natural y humanizado, de elementos de la biodiversidad y de geosítios, con valor científico, ecológico o educativo (artículo 16).

Parque Natural es un área que contiene predominantemente ecosistemas naturales o seminaturales, donde la preservación de la biodiversidad a largo plazo puede depender de la actividad humana, asegurando un flujo sostenible de productos naturales y servicios (artículo 17).

Reserva Natural es un área que contenga características ecológicas, geológicas y geomorfológicas, u otros atributos con valor científico, ecológico o educativo y que no esté habitada de forma permanente o significativa. (art. 18).

Paisaje Protegido es una zona que contiene paisajes resultantes de la interacción armoniosa de la naturaleza y el ser humano y que muestra gran valor estético, ecológico o cultural (artículo 19). 
puede ser de ámbito nacional, regional o local (Lei 11/1987). La suma del área protegida en cada una de las categorías eleva al 8,74\% la superficie peninsular portuguesa preservada.

A las zonas protegidas en el Portugal continental debemos sumar los espacios catalogados en las Regiones Autónomas de Azores y de Madeira, que tienen su propia normativa y sus propias denominaciones y en ningún caso cuentan con Parques Nacionales. La Red Regional de Áreas Protegidas de la Región Autónoma de Azores incluye 9 parques naturales y 1 parque marino y Madeira cuenta con un Parque Natural, 4 Reservas Naturales y un área Marina Protegida (Decreto Legislativo Regional 15/2007) ${ }^{18}$.

Tabla 3

LOS ESPACIOS NATURALES PROTEGIDOS EN ESPAÑA Y PORTUGAL

\begin{tabular}{|c|c|c|c|c|c|c|c|c|c|c|c|c|}
\hline & \multicolumn{9}{|c|}{ PORTUGAL } & \multirow{2}{*}{\multicolumn{3}{|c|}{$\frac{\text { ESPAÑNA }}{\text { TOTAL }}$}} \\
\hline & \multicolumn{2}{|c|}{ NACIONALES } & \multicolumn{2}{|c|}{ REGIONALES } & \multicolumn{2}{|c|}{ LOCALES } & \multicolumn{3}{|c|}{ TOTAL* } & & & \\
\hline & $\mathrm{N}^{\circ}$ & $\mathrm{Km}^{2}$ & $\mathrm{~N}^{\mathrm{o}}$ & $\mathrm{Km}^{2}$ & $\mathrm{~N}^{\circ}$ & $\mathrm{Km}^{2}$ & $\mathrm{~N}^{\mathrm{o}}$ & $\mathrm{Km}^{2}$ & $\% * *$ & $\mathrm{~N}^{\circ}$ & $\mathrm{Km}^{2}$ & $\% * *$ \\
\hline $\begin{array}{l}\text { Parque } \\
\text { Nacional }\end{array}$ & 1 & 695,92 & & & & & 1 & 695,92 & 0,78 & 15 & $3.646,26$ & 0,72 \\
\hline $\begin{array}{l}\text { Parque } \\
\text { Natural }\end{array}$ & 13 & 5935,20 & 1 & 247,67 & & & 14 & $6.182,87$ & 6,94 & 149 & $39.376,13$ & 7,78 \\
\hline $\begin{array}{l}\text { Reserva } \\
\text { Natural }\end{array}$ & 9 & 740,81 & & & 2 & 1,20 & 11 & 742,01 & 0,83 & 291 & $1.691,80$ & 0,33 \\
\hline $\begin{array}{l}\text { Paisaje } \\
\text { Protegido }\end{array}$ & 2 & 19,25 & 5 & 110,85 & 4 & 22,12 & 11 & 152,22 & 0,17 & 53 & $1.413,34$ & 0,28 \\
\hline $\begin{array}{l}\text { Monumentos } \\
\text { Naturales }\end{array}$ & 7 & 11,57 & & & & & 7 & 11,57 & 0,01 & 328 & 880,56 & 0,17 \\
\hline TOTAL & 32 & 7402,75 & 6 & 358,52 & 6 & 23,32 & 44 & $7.784,59$ & 8,74 & 836 & $47.008,09$ & 9,29 \\
\hline $\begin{array}{l}\text { A.Privada/ } \\
\text { Área Marina }\end{array}$ & 1 & 2,15 & & & & & & 2,15 & 0,00 & 1 & $2.349,50$ & 0,46 \\
\hline TOTAL & 32 & 7402,75 & 6 & 358,52 & 6 & 23,32 & 44 & $7.784,59$ & 8,74 & 837 & $49.357,59$ & 9,76 \\
\hline
\end{tabular}

*Sin contabilizar las zonas protegidas en las Regiones autónomas de Azores y Madeira.

**Porcentaje sobre la superficie total de cada país; en Portugal sin contabilizar las Regiones autónomas de Azores y Madeira.

Fuente: EUROPARC, 2014: 29, e Instituto da Conservação da Natureza e das Florestas -ICNF- 2014 ${ }^{19}$. Elaboración propia.

Monumento natural es un elemento natural que contiene uno o más aspectos, que por su singularidad, rareza o representatividad en términos ecológicos, estéticos, científicos o culturales, requiere su conservación y el mantenimiento de su integridad (artículo 20).

Área Protegida Privada son terrenos privados no incluidos en áreas clasificadas que respondan a los objetivos previsto en el artículo 12 (mantenimiento de la biodiversidad, de los ecosistemas y del patrimonio geológico así como de los paisajes) (artículo 21).

18 Las áreas protegidas en las dos regiones autónomas pueden consultarse en http://www.icnf.pt/portal/naturaclas/snac y también en http://www.azores.gov.pt/Gra/srrn-natureza/menus/secundario/\%C3\%81reas+Protegidas/ (Azores) y http://www.pnm.pt/index.php?option=com_content\&view=article\&id=26\&Itemid=44\&lang=pt (Madeira).

19 La información referida a las áreas clasificadas puede consultarse en http://www.icnf.pt/portal/ap y la cartografía en http://www.icnf.pt/portal/naturaclas/cart/ap-rn-ramsar-pt. 
Si miramos a España vemos que los dos primeros Parques Nacionales fueron reconocidos hace casi un siglo y hoy la red está integrada por quince en total ${ }^{20}$. Junto a esta figura la normativa estatal contempla asimismo las de Parque Natural, Reserva Natural, Área Marina Protegida, Monumento Natural y Paisaje Protegido ${ }^{21}$ con unas características muy similares a como están contempladas en la normativa portuguesa. Las similitudes se observan también en el territorio protegido por cada país en las distintas categorías, pues las diferencias tan abultadas en las cifras absolutas se diluyen casi por completo al relacionarlas con la superficie respectiva de España y Portugal ${ }^{22}$.

En ambos casos los Parques Nacionales ocupan poco más del 0,7\% del territorio y los Parques Naturales en torno al 7\%. Las principales diferencias las vemos en la Reservas Naturales, más representadas en Portugal, y en los Paisajes Protegidos y Monumentos Naturales donde la balanza se inclina del lado español, sobre todo en el último tipo señalado.

Pero en España a las figuras de protección recogidas en la normativa nacional, y trasladadas de manera similar a las normas autonómicas, hay que sumar aquellas otras incluidas en la legislación de las diferentes Comunidades Autónomas. No olvidemos que ellas tienen las competencias en esta materia y la mayoría incluye en su legislación otras figuras de protección, hasta 32 más que no se corresponden estrictamente con las señaladas y elevan tanto el número de espacios, de 837 a 1.831 (EUROPARC, 2014: anexo II. Listado de áreas

20 Los Parques Nacionales en el momento actual están regidos por la Ley 30/2014 que los define en su art. 4 como espacios naturales, de alto valor ecológico y cultural, poco transformados por la explotación o actividad humana que, en razón de la belleza de sus paisajes, la representatividad de sus ecosistemas o la singularidad de su flora, de su fauna, de su geología o de sus formaciones geomorfológicas, poseen unos valores ecológicos, estéticos, culturales, educativos y científicos destacados cuya conservación merece una atención preferente y se declara de interés general del Estado.

21 En España la Ley 42/2007 define las siguientes figuras:

Parques son áreas naturales, que, en razón a la belleza de sus paisajes, la representatividad de sus ecosistemas o la singularidad de su flora, de su fauna o de su diversidad geológica, incluidas sus formaciones geomorfológicas, poseen unos valores ecológicos, estéticos, educativos y científicos cuya conservación merece una atención preferente (artículo 30).

Reservas Naturales son espacios naturales, cuya creación tiene como finalidad la protección de ecosistemas, comunidades o elementos biológicos que, por su rareza, fragilidad, importancia o singularidad merecen una valoración especial (artículo 31).

Áreas Marinas Protegidas son espacios naturales designados para la protección de ecosistemas, comunidades o elementos biológicos o geológicos del medio marino, incluidas las áreas intermareal y submareal, que en razón de su rareza, fragilidad, importancia o singularidad, merecen una protección especial. Podrán adoptar esta categoría específica o protegerse mediante cualquier otra figura de protección de áreas prevista en esta Ley, en cuyo caso, su régimen jurídico será el aplicable a estas otras figuras, sin perjuicio de su inclusión en la Red de Áreas Marinas Protegidas (artículo 32).

Monumentos Naturales son espacios o elementos de la naturaleza constituidos básicamente por formaciones de notoria singularidad, rareza o belleza, que merecen ser objeto de una protección especial.

Se considerarán también Monumentos Naturales los árboles singulares y monumentales, las formaciones geológicas, los yacimientos paleontológicos y mineralógicos, los estratotipos y demás elementos de la gea que reúnan un interés especial por la singularidad o importancia de sus valores científicos, culturales o paisajísticos (artículo 33).

Paisajes Protegidos son partes del territorio que las Administraciones competentes, a través del planeamiento aplicable, por sus valores naturales, estéticos y culturales, y de acuerdo con el Convenio del paisaje del Consejo de Europa, consideren merecedores de una protección especial (artículo 34).

22 La comparación con la superficie total del país en el caso de Portugal se establece con la parte correspondiente a la Península Ibérica, pues los datos detallados de los espacios protegidos se restringen a dicho territorio. 
protegidas por Comunidades Autónomas) ${ }^{23}$, como la superficie protegida, de 4.935.759 Ha hasta las 6.535.193 Ha, el 12,9\% del territorio español (EUROPARC, 2014, 26) ${ }^{24}$.

Figura 6

ESPACIOS NATURALES. DISTRIBUCIÓN DE LA SUPERFICIE PROTEGIDA POR CATEGORÍAS

ESPAÑA

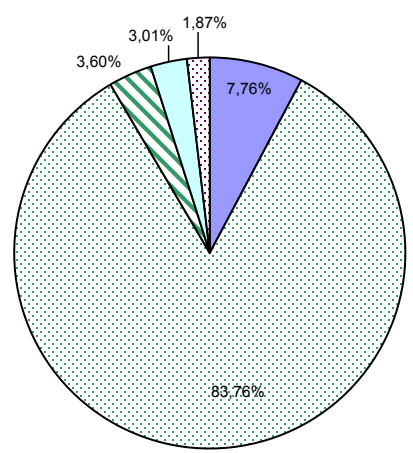

PORTUGAL

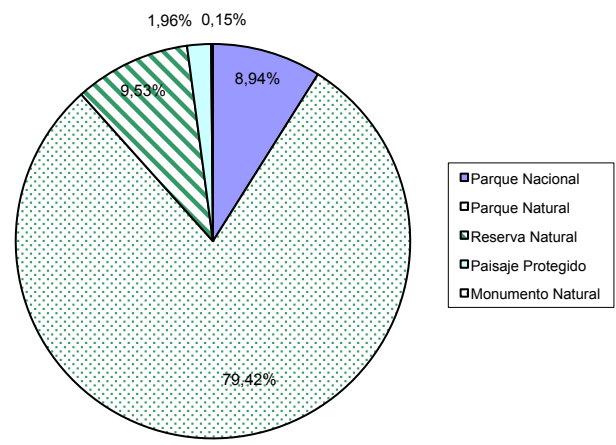

Fuente: EUROPARC, 2014: 29, e Instituto da Conservação da Natureza e das Florestas -ICNF- 2014.

Figura 7

CATEDRAL DE SALAMANCA, DECLARADA MONUMENTO EN 1887 E INCLUIDA EN LA CIUDAD VIEJA DE SALAMANCA (INSCRITA EN 1988 EN LA LISTA DEL PATRIMONIO MUNDIAL DE LA HUMANIDAD), Y SITIOS DE ARTE RUPESTRE PREHISTÓRICO DEL VALLE DEL CÔA Y DE SIEGA VERDE (ESPAÑA-PORTUGAL); DECLARADOS PATRIMONIO MUNDIAL DE LA HUMANIDAD EN 1998 y 2010
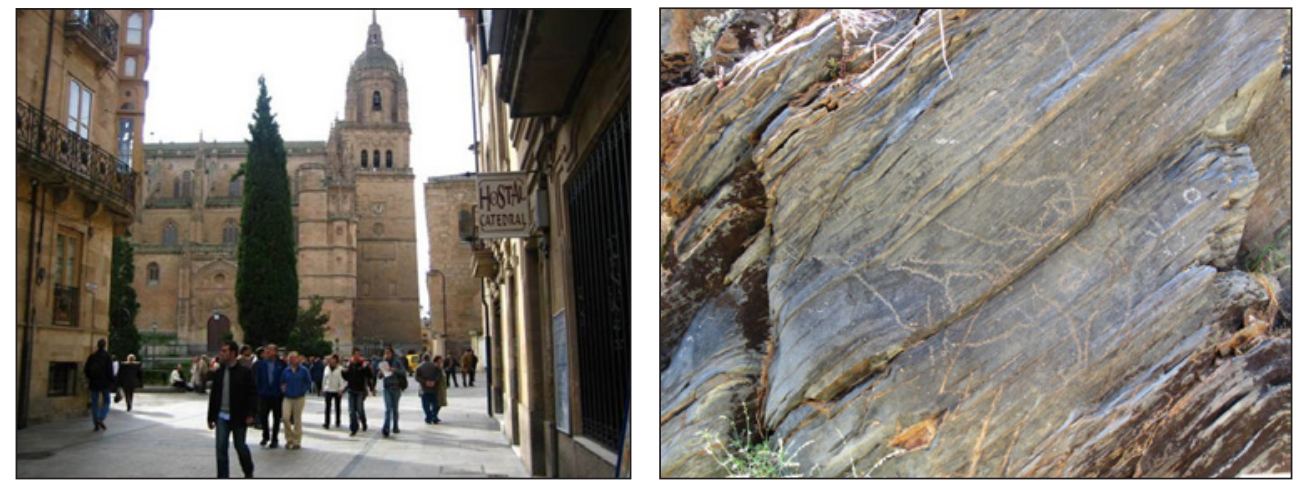

Fuente: elaboración propia.

23 En algunas Comunidades Autónomas entre las figuras de protección encontramos las cuevas, los parques periurbanos de conservación y ocio, los parques rurales o los árboles singulares, entre otras, que elevan sobremanera el número de espacios protegidos y, aunque en menor medida, también la superficie.

24 Datos de 2013 a los que habría que sumar los espacios protegidos en el año 2014 y 2015. 


\section{PATRIMONIO, PAISAJE Y ORDENACIÓN DEL TERRITORIO}

La riqueza intrínseca del patrimonio cultural y natural catalogado en España y Portugal y el afán por su conservación no puede hacernos olvidar que constituye asimismo un recurso con un elevado valor de uso, sobre todo para el turismo, y que este patrimonio territorial es hoy día un objetivo prioritario para la ordenación del territorio.

Desde instancias supranacionales se ha caminado por esta senda de la consideración conjunta de los diferentes aspectos integrados en el territorio, tal y como ya hemos apuntado al hablar de los paisajes culturales, y se avanza un paso más con la firma del Convenio Europeo del Paisaje ${ }^{25}$. En su artículo primero se especifica que «por «paisaje» se entenderá cualquier parte del territorio tal como la percibe la población, cuyo carácter sea el resultado de la acción y la interacción de factores naturales y/o humanos», y, por tanto, se fusionan los dos componentes del patrimonio. Más adelante se enfatiza en la relación que se establece entre el ser humano y el medio que habita, al tiempo que se introduce la dimensión social del paisaje, considerado como un elemento de bienestar, y se avanza en la necesidad de una gestión y ordenación responsable más allá de la mera conservación. Entre las medidas a considerar se pone el acento en la necesidad de «integrar el paisaje en las políticas de ordenación territorial y urbanística y en sus políticas en materia cultural, medioambiental, agrícola, social y económica, así como en cualesquiera otras políticas que puedan tener un impacto directo o indirecto sobre el paisaje» (Convenio Europeo del Paisaje, 2000: artículo 5.b).

Esta sensibilidad por el patrimonio territorial, por su ordenación y gestión, aparece en las políticas nacionales incluso con anterioridad a la firma del referido convenio del paisaje. En España, por ejemplo, la mayoría de las normas autonómicas de ordenación del territorio, aprobadas entre el año 1983 y el año 2001 (Martín, 2014), recogen entre sus objetivos, a imagen de lo señalado en la Carta Europea de Ordenación del Territorio, la gestión responsable de los recursos «con una atención especial a las bellezas naturales y al patrimonio cultural y arquitectónico» (Consejo de Europa, 1983: punto 16). Además, se señala que los instrumentos de ordenación deben incluir entre sus contenidos los criterios para la preservación de los recursos naturales y culturales, con una atención especial a su ámbito territorial y en concordancia con el desarrollo económico y urbanístico. Los mismos planteamientos se reconocen en los Planos Regionais de Ordenamento do territorio portugueses al incluir normas específicas para la protección y valoración del paisaje o criterios y estrategias para la intervención.

El patrimonio, el paisaje, como apuntábamos, debe contribuir también a la mejora de las poblaciones y como bien escaso adquiere un valor mercantil. Se convierte así en un recurso económico de primer orden, sobre todo en relación con el turismo, y también en un activo para el desarrollo sostenible (Carvalho, 2006: 210). El número de visitantes a los Parques Nacionales o a los monumentos y ciudades Patrimonio de la Humanidad ${ }^{26}$ hablan por si solos

25 El Convenio Europeo del Paisaje ha sido ratificado, entre otros muchos países, por España y Portugal: Decreto 4/2005, Convenção Europeia da Paisagem, e Instrumento de Ratificación del Convenio Europeo del Paisaje, 2008.

26 Recordar que el Parque Nacional del Teide y La Alambra de Granada reciben cada uno de ellos más de 2,5 millones de visitantes al año. http://www.alhambra-patronato.es/index.php/Balance-de-Visitantes-2014/1529/0/ y http://www.magrama.gob.es/es/red-parques-nacionales/la-red/gestion/visitantes.aspx. 
de la vinculación entre patrimonio, turismo y economía y a partir de ahí es fácil entender que el patrimonio inventariado es una riqueza que «adecuadamente gestionada, podría ser una baza clave para el desarrollo de muchas regiones del país, sobre todo, a partir de la utilización estratégica de las oportunidades que ofrece el turismo» (Observatorio de Sostenibilidad en España, 2009: 40).

Nos interesa resaltar, por tanto, esta consideración del patrimonio insertado en su territorio e integrado en las políticas territoriales y como desde esta perspectiva se incorpora a la planificación territorial a partir de la inclusión del paisaje cultural en la lista del Patrimonio Mundial de la Humanidad y, sobre todo, de la firma del Convenio Europeo del Paisaje. En Portugal, por ejemplo, el Programa Nacional da Política de Ordenamento do Territorio -PNPOT- asume que «el paisaje es un recurso, una plusvalía que asociada a formas de turismo y ocio, puede constituir un motor de desarrollo» (Cancela d'Abreu, Oliveira, Botelho y Afonso, 2011: 23).

Los ejemplos de cómo el paisaje es un capital al servicio del desarrollo sostenible son múltiples, solo hace falta echar la vista hacia los programas de desarrollo rural, no en vano en sus ejes estratégicos encontramos la revalorización del patrimonio y el turismo y a uno y otro lado de la raya ibérica los ejemplos de financiación de actuaciones en esta línea se multiplican (Hortelano, 2013).

Si ponemos la mirada en la ordenación del territorio de nuevo se suceden los instrumentos que incorporan el paisaje como un elemento clave, pero haremos solo dos referencias para España ${ }^{27}$ y una incursión en Portugal.

En las Directrices Esenciales de Castilla y León, aprobadas en el año 2008, se diferencia el patrimonio natural y el cultural pero lo tratan de manera similar o conjunta y se preocupan tanto por la salvaguarda como por su utilización con una base territorial. Así, entre los objetivos del modelo territorial encontramos «Proteger el patrimonio natural y cultural, señas de identidad de Castilla y León, como factores de atracción espacial y fundamentos de la calidad de vida, incentivando su puesta en valor mediante una perspectiva territorial organizadora» (Ley 3/2008: Anexo 1.3.d), y el capítulo III, denominado Hacia una Comunidad rica y diversa, se centra por entero en la «Protección de la Riqueza Natural y del Medio Ambiente» y en la «Protección y Puesta en Valor del Patrimonio Cultural». En él podemos leer que la diversidad y riqueza de sus espacios naturales y del patrimonio cultural, son un recurso básico que debe ser valorado mediante políticas que promuevan un uso sostenible e inteligente. A continuación se introduce el valor mercantil al señalar que se deben «promover acciones de desarrollo socioeconómico para los habitantes de los espacios naturales y de sus zonas de influencia socioeconómica» y marca como objetivo estratégico la «puesta en valor del patrimonio cultural, introduciendo una perspectiva territorial que favorezca su incidencia en el desarrollo local». La relación entre patrimonio y territorio se refuerza cuando se habla de la red de espacios naturales, la red de corredores ecológicos, la red de conjuntos históricos y la red de paisajes culturales en los que se vincula patrimonio rural, paisajes culturales y bienes culturales intangibles (Ley 3/2008: Anexo 3.1., 3.2., 3.4., 3.8., 3.9. y 3.10.).

27 El análisis de la incorporación de las líneas marcadas por el Convenio Europeo del Paisaje a los instrumentos de ordenación del territorio en las Comunidades Autónomas puede verse en Observatorio de Sostenibilidad en España, 2009: 65-133). 
En Portugal encontramos preocupaciones muy parecidas y desde la política y la administración se han dado orientaciones para la inclusión de los presupuestos del Convenio Europeo del Paisaje en la ordenación del territorio (Cancela D’abreu, Oliveira, Botelho y Afonso, 2011). A modo de ejemplo nos fijamos en el Plano Regional de Ordenamento do Território do Oeste e Vale do Tejo que, al igual que en el caso anterior, incorpora los desvelos por la conservación y por la consideración del patrimonio natural y cultural como un recurso para el desarrollo regional; entre las opciones para el desarrollo del territorio se incluye «Estimular o surgimento de redes de valorização do património histórico, cultural (material e imaterial) e natural» (42) ${ }^{28}$ Aunque en las referencias al patrimonio se separa lo natural de lo cultural si aparece el componente territorial y el paisaje, y, como sucede en Castilla y León, se articulan «"Corredores Ecológicos Estruturantes" (CEE) de dimensão regional e nacional» (78) y se establecen directrices relacionadas con el paisaje en el apartado de normas específicas de carácter sectorial: «1-Assumir a paisagem como um elemento chave na identidade e carácter regional e sub-regional, e um recurso relevante a nível da avaliação de projectos, processos de alteração de uso de solo e desenvolvimento territorial» (159).

En el tercer caso elegido, el Plan de Ordenación del Territorio de Andalucía, se avanza aún más en la consideración conjunta de patrimonio natural y cultural, que desemboca en el concepto de patrimonio territorial entendido como recurso: «recursos patrimoniales (culturales, ambientales y paisajísticos)». Antes nos recuerda «el tradicional entendimiento de los bienes patrimoniales como elementos aislados, hitos sin conexión con el territorio y con el resto de bienes patrimoniales» $\mathrm{y}$ «el todavía escaso y poco definido impulso a la gestión del patrimonio como un recurso al servicio del desarrollo regional». Para superar estas visiones compartimentadas el Plan apuesta por «políticas de gestión patrimonial integradoras, articuladoras del territorio, y capaces de contribuir de manera eficaz a los procesos de desarrollo regional y local» y por una líneas estratégicas que integren «la protección de los bienes culturales y naturales y los ejes que los interconectan y hacen accesibles en una red territorialmente coherente que conforme un Sistema de Patrimonio Territorial» en el que se incluyen referencias territoriales concretas y estrategias de planificación y gestión ${ }^{29}$.

A través de estos ejemplos queda claro que el patrimonio territorial, el paisaje, se ha incorporado en el momento actual a la planificación, al menos a los instrumentos de ordenación del territorio a escala regional.

\section{CONCLUSIONES}

El análisis de las recomendaciones y acuerdos sobre la herencia histórica, artística, natural y cultural recibida de nuestros antepasados nos ha permitido contrastar el camino que

28 Las citas textuales que se hacen del Plano Regional de Ordenamento do território do Oeste e Vale do Tejo están tomadas de Fonseca y Carmo, 2009; entre paréntesis solo se señala la página.

29 Las citas textuales están tomadas del Plan de Ordenación del Territorio de Andalucía -POTA- aprobado por Decreto 209/2006. En concreto del Título III-Las Estrategias de Desarrollo Territorial, Capítulo 3-Sistema Regional de Protección del Territorio, Sección $2^{\text {a }}$-Sistema del Patrimonio Territorial. El Plan también puede consultarse en la página web de la Junta de Andalucía, en su sección de Ordenación del Territorio, http://www.juntadeandalucia.es/ medioambiente/site/portalweb/menuitem.7e1cf46ddf59bb227a9ebe205510e1ca/?vgnextoid=f2d9f7ffa3828310 Vgn VCM1000001325e50aRCRD\&vgnextchannel=7e7e8a3c73828310VgnVCM2000000624e50aRCRD\#apartadoc02e f7ffa3828310VgnVCM1000001325e50a 
ha llevado del monumento al paisaje y al patrimonio territorial y como han cambiado las preocupaciones de la sociedad respecto al legado recibido: de la conservación para evitar la destrucción o el expolio a su uso en beneficio del desarrollo. En este tránsito se ha pasado también de la valoración de los elementos singulares de manera puntual e independiente a la consideración conjunta de todos ellos y su relación con el territorio en el que se ubican. En el contexto internacional la Carta de Atenas de 1931 es un primer hito y la incorporación de los paisajes culturales al Patrimonio Mundial de la Humanidad en el seno de la UNESCO en 1992 uno de los últimos. A ellos se suma el Convenio Europeo del Paisaje del año 2000 como un referente más próximo tanto en el tiempo como en el espacio.

Este recorrido a escala internacional lo hemos constatado asimismo en la escala nacional, tomando como ejemplos España y Portugal. En ambos países el desarrollo normativo y la catalogación de bienes han seguido en buena medida los pasos marcados por las instancias supranacionales y se han protegido tanto bienes naturales como históricos, artísticos o culturales según las épocas y en consonancia con los presupuestos vigentes en cada momento. La preocupación inicial se retrotrae a finales del siglo XVIII y principios de XIX y está vinculada a las Academias de Historia y del Arte. En esos momentos se pretende salvaguardar los monumentos -las antigüedades- de la destrucción y para conseguirlo se catalogan a título individual; la Catedral de León, en España, o el Monasterio de Batalha, en Portugal, son ejemplos de cuanto decimos. La declaración de la Montaña de Covadonga como Parque Nacional de 1916 tiene asimismo ese carácter de excepcionalidad (singularidad) y nos habla al mismo tiempo de la dicotomía entre patrimonio natural y patrimonio histórico-artístico. Con posterioridad se observa la incorporación de las recomendaciones emanadas en la esfera internacional a las normativas nacionales, que transciende a los bienes catalogados: el Paisaje Natural de la Serra de Tramuntana o la región vinícola del Alto Douro son en esta ocasión ejemplos de ese carácter integral del patrimonio, que tiene en cuenta los valores culturales y la aportación social a la construcción del paisaje.

El último paso en este devenir es la vinculación del patrimonio con el territorio como fruto de la construcción social en su dimensión histórica (Ortega 1998: 43) que debe contribuir al bienestar de la población. El patrimonio territorial, el paisaje, se convierten así en un recurso al servicio del desarrollo y se integra en las políticas de ordenación territorial como se ha podido comprobar con las propuestas incluidas en diferentes planes de ordenación territorial a escala regional, tanto españoles como portugueses.

En definitiva, se ha comprobado ese paso del monumento al paisaje, de lo singular a la interacción de los factores naturales y humanos y su integración en las políticas territoriales que consideran al patrimonio como un aval para el desarrollo regional y local.

\section{REFERENCIAS}

AAVV. (2000): Turismo Cultural: El Patrimonio Histórico como Fuente de Riqueza. Valladolid. Fundación del Patrimonio Histórico de Castilla y León.

BARBERO FRANCO, A. M. (2011): La gestión del patrimonio histórico como instrumento para un desarrollo sostenible. Un caso práctico: el proyecto de desarrollo local «os ambientes do Ar». Salamanca. Ediciones Universidad de Salamanca. Colección Vitor. Disponible en https://books.google.pt/books?id=bXKtr77LDy8C\&pg=PA599\&lpg=PA599 
$\&$ dq=Decretode $+24+$ de + outubro + de $+1901+$ monumentos $\&$ source=bl\&ots $=q 1 \mathrm{GrG}$ - $x \mathrm{l}-\mathrm{R}$ \&sig=NzQ3Be0b-IRCDzUYYKTyW588kRU\&hl=es\&sa=X\&ei=PgW5VO2NM4nvUrqgYAI\&ved=0CC4Q6AEwAg\#v=onepage $\&$ q=Decretode $\% 2024 \% 20 \mathrm{de} \% 20$ outubro $\% 20$ de $\% 201901 \% 20$ monumentos $\& \mathrm{f}=$ false

BARRERO RODRÍGUEZ, C. (1990): La ordenación jurídica del patrimonio histórico español. Madrid. Cívitas.

BECERRA GARCÍA, J.M. (1999): «La legislación española sobre patrimonio histórico, Origen y Antecedentes. La Ley del Patrimonio Histórico Andaluz» en Actas de las V Jornadas sobre Historia de Marchena. El patrimonio y su conservación, 9-30. Disponible en http://www.bibliotecaspublicas.es/marchena/imagenes/V_1_Becerra_legislacion.pdf

CABERO DIÉGUEZ, V. y JACINTO, R.: (2015): «Apresentação». Iberografía $n^{o}$ 30, Nas fronteras da esperanza: paisagems e patrimônios, permanências e mobilidades, 7-15.

CARTA DE ATENAS, (1931): Carta de Atenas para la restauración de monumentos históricos. Convención de Monumentos de Arte e Historia. Primera Conferencia Internacional de Arquitectos y Técnicos de Monumentos Históricos, Atenas, 1931. Disponible en http:/www.unesco.org/culture/natlaws/media/pdf/guatemala/guatemala_carta_de_atenas_1931_spa_orof.pdf.

CARTA DE VENECIA (1965): Carta de Venecia para la conservación y la restauración de monumentos y sitios. II Congreso internacional de arquitectos y técnicos de monumentos históricos, Venecia 1964. Adoptada por ICOMOS - Consejo Internacional de Monumentos y Sitios- en 1965. Disponible en http://www.international.icomos.org/charters/ venice_sp.pdf

CARVALHO TOMAS, P.M. (2006): «Património cultural, ordenamento e desenvolvimento: Uma nova visão e valorização do território». Cadernos de Geografia, n ${ }^{24-25,209-226 .}$

CARVALHO TOMAS, P.M. (2008): «Património cultural e estratégias de desenvolvimento em Portugal: balanço e novas perspectivas», en Diez años de cambios en el Mundo, en la Geografía y en las Ciencias Sociales, 1999-2008. Actas del X Coloquio Internacional de Geocrítica, Universidad de Barcelona. Disponible en http://www.ub.es/geocrit/-xcol/289.htm

CONSEJO DE EUROPA (1983) Carta Europea de Ordenación del Territorio. Aprobada en Torremolinos el 20 de Mayo.

CONSEJO DE EUROPA (2000): Convenio Europeo del Paisaje, acordado en Florencia el 20 de octubre. Traducción oficial consultada el 25 de mayo de 2015 en la página del Ministerio de Educación, Cultura y Deporte del Gobierno de España http://www.mecd. gob.es/cultura-mecd/dms/mecd/cultura-mecd/areas-cultura/patrimonio/Convenio_europeo_paisaje.pdf.

CUSTÓDIO, J. (1993): «Salvaguarda do Património - Antecedentes históricos», Dar futuro ao passado. Lisboa. Instituto Português do Património Arquitectónico e Arqueológico.

CANCELA D'ABREU, A., OLIVEIRA, R., BOTELHO, M.A., y AFONSO, M. (2011): A Paisagem na revisão dos PDM. Orientações para a implementação da Convenção Europeia da Paisagem no âmbito municipal. Direcçao-Geral do Ordenamento do Território e Desenvolvimento urbano. Documentos de Orientação 02/ 2011. Edición digital. Disponible en http:// www.dgterritorio.pt/static/repository/2013-12/2013-12-02090612_54ab20bb-0b19-4b78b3b7-038c54e07421\$\$A2CC10BC-DE36-4DAE-BD88-1936AB037C38\$\$26CFA830DB92-4E32-99E7-E870AEF50360\$\$File\$\$pt\$1.pdf 
EUROPARC (2014): Anuario 2013 del estado de las áreas protegidas en España. Madrid. Fundación Fernando González Bernáldez.

INSTITUTO DA CONSERVAÇÃO DA NATUREZA E DAS FLORESTAS -ICNF- (2014): Rede Nacional ce Áreas Protegidas -RNAP-. Disponible en http://www.icnf.pt/portal/ap (consultado el 17 de mayo de 2015).

INSTITUTO NACIONAL DE ESTATÍSTICA, (2014): Estatísticas de Cultura, 2013. Lisboa. Disponible en http://www.ine.pt/xportal/xmain?xpid=INE\&xpgid=ine publicacoes\&PUBLICACOESpub_boui=210767363\&PUBLICACOEStema $=55554 \& \mathrm{P}$ UBLICACOESmodo=2. (consultado el 13 de mayo de 2015).

FERREIRA PIRES, V.M. (2013): «Políticas públicas de patrimônio cultural em Portugal: da gênese à maioridade -Uma análise sobre três programas e dezenove anos de intervenções». Revista Sociais e Humanas. Centro de Ciências Sociais e Humanas da Universidade Federal de Santa Maria, vol.26, n 2, 274-290.

FLORIDO TRUJILLO, (2013): «El patrimonio territorial en el plan de ordenación del territorio de Andalucía: indefiniciones y dificultades para un conocimiento preciso». Boletín de la Asociación de Geógrafos Españoles, nº 63, 173-201.

FOWLER, P.J. (2003): World Heritage Cultural Landscapes 1992-2002. Paris. UNESCO World Heritage Centre, Papers 6. Disponible en http://unesdoc.unesco.org/ images/0013/001331/133121e.pdf.

FRANÇA, J.A. (1996): «O património cultural - sentido e evolução», en O Direito do Património Cultural (Miranda, J.). Lisboa, Instituto Nacional de Administração, 22-49.

GARCÍA FERNÁNDEZ, J. (2007): "La regulación y la gestión del Patrimonio HistóricoArtístico durante la Segunda República (1931-1939)”. e-rph, $\mathrm{n}^{\circ}$ 1, diciembre 2007. Revista electrónica de protección del patrimonio. Disponible en http://www.revistadepatrimonio.es/revistas/numero1/legislacion/estudios/articulo.php.

GÓMEZ-MENDOZA, J. (2013): «Del patrimonio paisaje a los paisajes patrimonio». Documents d'Anàlisi Geogràfica, vol. 59/1, 5-20.

HORTELANO MINGUEZ,L.A. (2013): «Las actividades turísticas en la zona fronteriza de Castilla y León con las regiones norte y centro de Portugal: un espacio interior y de baja densidad poblacional» en: Turismos de Interior. Planificación, comercialización y experiencias (Melgosa Arcos, F. J., coord.). Madrid. Editorial Pirámide, capítulo 6, 139-157.

IPPAR, (1994): Patrimônio arquitectónico e arqueológico. Informar para proteger. Lisboa. Instituto Português do Patrimônio Arquitectónico e Arqueológico.

LABACA ZABALA, M. L. (2013): «La protección del Patrimonio Etnográfico en España y en las Comunidades Autónomas: Especial referencia al País Vasco y Andalucía», RIIPAC, $\mathrm{n}^{\mathrm{o}} 2$ 2, 105-148. Revista electrónica disponible en http://www.eumed.net/rev/riipac.

LÓPEZ BRAVO, C. (1999): «Interrelación de las categorías legales de protección del Patrimonio Cultural en España». Boletín del Instituto Andaluz del Patrimonio Histórico, nº 27, 9-30.

MARTÍN JIMÉNEZ, M. I. (2014): "La ordenación del territorio en las comunidades autónomas. Desarrollo normativo". Polígonos, Revista de Geografía, n 26, 321-348.

MINISTERIO DE EDUCACIÓN, CULTURA Y DEPORTE (2014): Anuario de estadísticas culturales 2014. Madrid. Disponible en http://www.mecd.gob.es/servicios-al-ciudadano$\mathrm{mecd} / \mathrm{dms} / \mathrm{mecd} / \mathrm{servicios}-$ al-ciudadano-mecd/estadisticas/cultura/mc/naec/2014/Anuario_de_estadisticas_culturales_2014.pdf 
MINISTERIO DE MEDIO AMBIENTE (2003): Atlas de los paisajes de España. Madrid.

MENDES, J.A. (2000): «Uma nova perspectiva sobre o património cultural: preservação e requalificação de instalações industriais». Gestão e Desenvolvimento Arqueologico, $\mathrm{n}^{\circ}$ 9, 197-211.

MULERO MENDIGORRI, A., GARZÓN GARCÍA, R. y NARANJO RAMÍREZ, J. (2011): «El Sistema de Patrimonio Territorial y su significado en el contexto de las nuevas directrices de ordenación del territorio en Andalucía (España)». UGI-2011. Regional Geographic Conference. Santiago de Chile. Disponible en la página oficial del repositorio institucional de la universidad de Córdoba Ahttp://helvia.uco.es/xmlui/ handle/10396/7944?show=full

MUÑOZ COSME, A. (2012): «Catálogos e inventarios del patrimonio en España» en Catálogo monumental de España, (1900-1961). Investigación restauración y difusión (LópezYarto Elizalde, Coord) Madrid. Ministerio de Cultura, Secretaría general técnica, 13-36. Disponible en file://C:/Users/User/Downloads/14089_19\%20(1).pdf; http://es.calameo. com/read/000075335c05d3862c772.

OBSERVATORIO DE SOSTENIBILIDAD EN ESPAÑA (2009): Patrimonio natural, cultural y paisajístico. Claves para la sostenibilidad territorial. Madrid. Disponible en la página de la Universidad el País Vasco, http:/www.upv.es/contenidos/CAMUNISO/info/ U0556177.pdf

ORTEGA VALCÁRCEL, J. (1998): «El patrimonio territorial: el territorio como recurso territorial y económico». Revista Ciudades, $\mathrm{n}^{\circ} 4,33-48$.

PARRONDO ACERO, C. (Director) (1973): Inventario del Patrimonio artístico y arqueológico de España. Madrid. Servicio de publicaciones del Ministerio de Educación y Ciencia.

QUIROSA GARCÍA, M.V. (2005): Historia de la protección de los bienes culturales muebles: definición, tipologías y principios generales de su estatuto jurídico. Granada. Editorial de la Universidad de Granada.

RABAS F. (1926): «Relación de los Monumentos españoles declarados nacionales o arquitectónico-artísticos y de los que en uno u otro concepto considera merecedores de serlo la Real Academia de Bellas Artes de San Fernando». Boletín de la Real Academia de Bellas Artes de San Fernando, n ${ }^{\circ} 79,130-144$.

ROCA ROCA, E. (1987): El patrimonio Artístico y Cultural. Madrid. Tecno.

TROITIÑO VINUESA, M. A. (2008): «Estrategias sostenibles en destinos patrimoniales. De la promoción a la gestión integrada e innovadora». Estudios Turísticos, $n^{\circ}$ 172-173, 225-232.

UNESCO (1972): Convención sobre la protección del Patrimonio Mundial Cultural y Natural. Conferencia General de la Organización de las Naciones Unidas para la Educación, la Ciencia y la Cultura. $17^{\circ}$ Reunión celebrada en París del 17 de Octubre al 22 de Noviembre de 1972 Paris. Disponible en http://whc.unesco.org/archive/convention-es. pdf.

UNESCO (1992): Seizième session Comité du patrimoine mondial. Conventión concernant la protection du patrimoine mondial, culturel et naturel. Santa Fe-Estados Unidos, 7-14 decémbre. Disponible en http://whc.unesco.org/fr/sessions/.

UNESCO (1994): Operational Guidelines for the Implementation of the World Heritage Convention. Disponible en http://whc.unesco.org/archive/opguide94.pdf. 
UNESCO (2005): Directrices Prácticas para la aplicación de la Convención del Patrimonio Mundial, Anexo III. Comité Intergubernamental de protección del Patrimonio Mundial cultural y natural. Centro del Patrimonio Mundial. Disponible en http://whc.unesco.org/ archive/opguide05-es.pdf.

UNESCO (2014): Gestión del patrimonio Mundial Natural. Paris. Disponible en whc. unesco.org/document/130488.

ZOIDO NARANJO, F. (Dir.) (2002): Paisaje y ordenación del territorio. Sevilla. Servicio de Publicaciones de la Consejería de Obras Públicas y Transportes de la Junta de Andalucía.

\section{NORMATIVA}

\section{Española}

CONSTITUCIÓN de la República Española, de 9 de diciembre de 1931. Gaceta de Madrid, $\mathrm{n}^{\circ} 344$, de 10 de diciembre de 1931.

CONSTITUCION Española de 27 de diciembre de 1978. BOE, $\mathrm{n}^{\circ} 311.1$, de 29 de diciembre de 1978.

DECRETO, de 3 de junio de 1931, por el que se declaran los Monumentos histórico-artísticos pertenecientes al Tesoro Artístico Nacional. Gaceta de Madrid, n ${ }^{\circ}$ 155, de 4 de junio de 1931.

DECRETO 206/2006, de 28 de noviembre, por el que se adapta el Plan de Ordenación del Territorio de Andalucía a las Resoluciones aprobadas por el Parlamento de Andalucía en sesión celebrada los días 25 y 26 de octubre de 2006 y se acuerda su publicación. BOJA, $\mathrm{n}^{\circ} 14$, de 29 de diciembre de 2006.

INSTRUMENTO de Ratificación del Convenio Europeo del Paisaje (número 176 del Consejo de Europa), hecho en Florencia el 20 de octubre de 2000, de 6 de noviembre de 2007. BOE, $\mathrm{n}^{\mathrm{o}} 31$, de 5 de febrero de 2008.

LEY de 7 de diciembre de 1916, de Parques Nacionales. Gaceta de Madrid, nº 343, de 8 de diciembre 1916.

LEY de 7 de julio de 1911 sobre excavaciones arqueológicas y científicas. La Gaceta de Madrid, $\mathrm{n}^{\circ} 159$, de 8 de julio de 1911.

LEY de 4 de marzo de 1915 de Monumentos Arquitectónicos Artísticos. La Gaceta de Madrid, $\mathrm{n}^{\circ}$ 64, de 5 de marzo de 1915.

LEY de 10 de diciembre de 1931 sobre enajenación de bienes artísticos, arqueológicos e históricos de más de cien años de antigüedad. La Gaceta de Madrid, n ${ }^{\circ}$ 346, de 12 de diciembre de 1931.

LEY de 13 de mayo de 1933, relativa al Patrimonio Artístico Nacional. La Gaceta de Madrid, n. ${ }^{\circ} 145$, de 25 de mayo de 1933.

LEY de 22 de diciembre de 1955 sobre conservación del patrimonio histórico-artístico. BOE, $\mathrm{n}^{\mathrm{o}} 359$, de 25 de diciembre de 1955.

LEY 15/1975, de 2 de mayo, de Espacios naturales protegidos. $B O E \mathrm{n}^{\circ} 107$, de 5 de mayo de 1975.

LEY 16/1985 de 25 de junio, del Patrimonio Histórico Español. BOE nº 155, de 29 de junio de 1985 .

LEY 4/1989 de 27 de marzo, de Conservación de los Espacios Naturales y de la Flora y Fauna Silvestres. BOE $\mathrm{n}^{\mathrm{o}} 74$, de 28 de marzo de 1989. 
LEY 4/1990 de 30 mayo. Regulación del Patrimonio Histórico de Castilla-La Mancha. COCM, nº 41, de 13 de junio de 1990.

LEY 7/1990 de 3 julio 1990. Regulación del Patrimonio Cultural Vasco. BOPV, núm. 157, de 6 de Agosto de 1990.

LEY 3/2008 de 17 de junio, de aprobación de las Directrices Esenciales de Ordenación del Territorio de Castilla y León. BOCyL, suplemento al n ${ }^{\circ} 120$, de 24 de junio de 2008.

LEY 42/2007 de 13 de diciembre, del Patrimonio Natural y de la Biodiversidad. BOE, $\mathrm{n}^{\circ}$ 299, de 14 de diciembre del 2007.

LEY 30/2014 de 3 de diciembre, de Parques Nacionales. BOE, ${ }^{\circ} 293$, de 4 de diciembre de 2014.

REAL CÉDULA de S(u) M(ajestad) y Señores del Consejo, por la cual se aprueba y manda observar la Instrucción formada por la Real Academia de la Historia sobre el modo de recoger y conservar los monumentos antiguos descubiertos ó que se descubran en el Reyno (Imprenta Real de 6 de julio de 1803) Jorge Maier Allende (comentario y transcripción) Disponible en http://www.cervantesvirtual.com/obra-visor/real-cedula-de-sumajestad-y-senores-del-consejo-por-la-qual-se-aprueba-y-manda-observar-la-instru-0/ html/00224e2e-82b2-11df-acc7-002185ce6064_2.html.

REAL DECRETO-LEY de 9 de agosto de 1926, relativo al Tesoro Artístico Arqueológico Nacional. La Gaceta de Madrid, nº 227, de 15 de agosto de 1931.

REAL ORDEN 176 de 15 de julio de 1927, de Sitios de interés nacional. La Gaceta de Madrid, $\mathrm{n}^{\mathrm{O}} 203$, de 22 de julio de 1927.

\section{Portuguesa}

DECRETO de 24 de outubro de 1901 a crear o Conselho dos Monumentos Nacionais Na obra monumentos nacionaes portuguezes. Legislação. Imprensa Nacional 1910. Tomadas referencias de https://books.google.pt/books?id=NvrKKADg2M4C\&pg=PA221\&lpg=PA22 $1 \& \mathrm{dq}=$ Decretode $+24+\mathrm{de}+$ outubro+de $+1901+$ monumentos $\&$ source $=$ bl\&ots $=5 \mathrm{DpWKUv}$ x7i\&sig=jb0zvxqsd0j2NXdD_5mDIQbuf_M\&hl=es\&sa=X\&ei=PgW5VO2NM4nvUrqgYAI\&ved=0CCkQ6AEwAQ\#v=onepage \&q=Decretode $\% 2024 \% 20 \mathrm{de} \% 20$ outubro\%20de\%201901\%20monumentos\&f=false.

DECRETO de 27 de setembro de 1906, de clasificação dos monumentos. Diário do Governo, $1^{\text {a }}$ série, $n^{\circ} 228$, de 9 de outubro de 1906.

DECRETO de 16 de junho de 1910, que aprovou oficialmente a classificação dos monumentos nacionais. Diário do Governo, n 136 , de 23 de junho de 1910.

DECRETO 21.875 de 18 de novembro de1932, para estabelecer zonas de protecção para os edifícios públicos de reconhecido valor arquitectónico. Diário do Governo, I série n ${ }^{\circ} 271$, de 18 de novembro de 1932.

DECRETO 187/71 de 8 de maio, de creaçao do Parque nacional de Peneda Gerês. Diário do Governo, I série n ${ }^{\circ} 108$, de 8 de maio de 1971.

DECRETO 4/2005 de 14 de fevereiro, Convenção Europeia da Paisagem, feita em Florença em 20 de Outubro de 2000. Diário da República, I série $\mathrm{n}^{\circ} 33$, de 14 de fevereiro de 2005.

DECRETO LEGISLATIVO REGIONAL 15/2007/A. Rede Regional de Áreas Protegidas dos Açores. Diário da República, 1ª́rie nº 120, de 25 de junho de 2007. 
DECRETO-LEI 19/93 de 23 de janeiro, que criou a Rede Nacional de Áreas Protegidas (RNAP). Diário da República, $1^{\text {a }}$ série A n ${ }^{\circ}$ 19, de 23 de janeiro de 1993.

DECRETO-LEI 142/2008 de 24 de julio, estabelece o regime jurídico da conservação da natureza e da biodiversidade. Diário da República, $1^{\mathrm{a}}$ série $\mathrm{n}^{\circ} 142$, de 24 de julho de 2008.

LEI 9/70 de 19 de junho, dos parques nacionais e outros tipos de reservas. Diário da República, $1^{\text {a }}$ série $\mathrm{n}^{\mathrm{o}} 141$, de 19 de junho de 1970.

LEI 13/85 de 6 de julho do patrimônio Cultural português. Diário da República, I série n ${ }^{\circ}$ 153 , de 6 de julho de 1985 .

LEI 11/87 de 7 de abril, de bases do ambiente. Diário da República, I serie A n ${ }^{\circ} 81$, de 7 de abril de 1987.

LEI 107/2001 de 8 de setembro. Estabelece as bases da política e do regime de protecção e valorização do património cultural. Diário da República, I serie A n ${ }^{\circ} 209$, de 8 de setembro de 2001.

LEI 19/2014 de 14 de abril. Define as bases da política de ambiente. Diário da República, I série $\mathrm{n}^{\mathrm{0}} 73$, de 14 de abril de 2014.

RESOLUÇÃO DO CONSELHO DE MINISTROS n. ${ }^{\circ}$ 64-A/2009 Plano Regional de Ordenamento do Território do Oeste e Vale do Tejo (PROTOVT). Diário da República, I serie $\mathrm{n}^{\mathrm{o}} 151$, de 6 de agosto de 2009. 